\title{
Preserving Narrative Identity for Dementia Patients: Embodiment, Active Environments, and Distributed Memory
}

\author{
Richard Heersmink
}

Received: 17 October 2021 / Accepted: 18 January 2022 / Published online: 9 February 2022

(C) The Author(s) 2022

\begin{abstract}
One goal of this paper is to argue that autobiographical memories are extended and distributed across embodied brains and environmental resources. This is important because such distributed memories play a constitutive role in our narrative identity. So, some of the building blocks of our narrative identity are not brain-bound but extended and distributed. Recognising the distributed nature of memory and narrative identity, invites us to find treatments and strategies focusing on the environment in which dementia patients are situated. A second goal of this paper is to suggest various of such strategies, including lifelogging technologies such as SenseCams, life story books, multimedia biographies, memory boxes, ambient intelligence systems, and virtual reality applications. Such technologies allow dementia patients to remember their personal past in a way that wouldn't be possible by merely relying on their biological memory, in that way aiding in preserving their narrative identity and positively contributing to their sense of well-being.
\end{abstract}

Keywords Dementia - Alzheimer's disease · Extended mind $\cdot$ Narrative identity $\cdot$ Evocative objects $\cdot$ Healthcare policy $\cdot$ Emerging technologies

R. Heersmink $(\varangle)$

Department of Philosophy, Monash University,

Melbourne, Australia

e-mail: Richard.Heersmink@monash.edu

\section{Introduction}

On one level of analysis, who we are, our identity, is constituted by our personal narrative [1]. The building blocks of this narrative are autobiographical memories that are meaningfully connected into a narrative structure. Alzheimer's disease and other forms of dementia negatively impact on various cognitive capacities, including autobiographical memory. If dementia disintegrates a person's autobiographical memories and if these memories constitute the narrative, then dementia also disintegrates one's narrative identity [2]. Empirical research shows that the disintegration of one's narrative identity has negative consequences for the well-being of dementia patients [3].

One way to try to counter the detrimental effects of dementia on autobiographical memory and narrative identity is by using evocative objects [4]. These are objects that are associated with past experiences, including photos, souvenirs, clothing, artworks, diaries, mementos, and other memory evoking objects [5]. Interacting with evocative objects can aid dementia patients in accessing memories that are otherwise inaccessible or they can store autobiographical information that is no longer available in the embodied brain because the connectionist memory trace has decayed. In the latter case, autobiographical memories can, under certain circumstances, be distributed across embodied agent and evocative object [6]. Helping to maintain distributed memories is a promising way to aid dementia patients in preserving their 
narrative identity. This, in turn, will have a positive effect on their well-being. By drawing on empirical literature from cognitive psychology and human-technology interaction, this paper suggests a number of ways to do this.

This paper has the following structure. First, I argue that, on one level of analysis, our identity has a narrative structure "Narrative Identity". Second, I argue that the autobiographical memories constituting our narrative are extended and distributed across embodied agents interacting with evocative objects "Distributed Memory". Third, drawing on empirical research, I outline how dementia disintegrates memory and narrative identity, thereby significantly decreasing the well-being of the person "Dementia and Narrative Identity". Fourth, I suggest an approach, including some recommendations, to help dementia patients deal with their memory and identity loss. This approach focusses on maintaining the relations between dementia patients and their evocative objects "Strategies For Dealing With Memory and Identity Loss".

\section{Narrative Identity}

Schechtman [1] importantly distinguishes three questions regarding personhood. First, the identification question: what are the defining properties of persons? Second, the reidentification question: what makes a person the same person over time? Third, the characterisation question: what makes a person the person he or she is? Persons are embodied creatures with the capacity for conscious states, including affective states such as pleasure and pain, who can reason about and distinguish themselves from the world in which they are situated. Persons are unique entities and membership to the category of persons comes with privileges and obligations. The notion of personhood is important because persons are the canonical examples of entities with moral status and therefore ought to be treated as to respect their dignity, privacy, autonomy, and well-being.

Whether we are the same person over time is a complex metaphysical question that, I think, should allow for degrees of continuity. In answering the reidentification question, we are examining the relation between two time slices of a person, thereby tracking the numerical identity of a person over time. Various answers have been suggested, proposing sameness of our biological organism [7] and the continuity of our mental states (e.g., [8] as criteria of the continuity of our personhood over time. Enlightenment philosopher John Locke develops the first systematic analysis of continuity of personhood over time in terms of psychological properties. He writes:

“...in this alone consists personal Identity, i.e. the sameness of rational Being: And as far as this consciousness can be extended backwards to any past Action or Thought, so far reaches the Identity of that Person; it is the same self now it was then; and 'tis by the same self with this present one that now reflects on it, that that Action was done" ([9], p. 341).

Locke thus claims that we are the same person over time when our consciousness extends back to past actions and thoughts, which is usually interpreted as involving autobiographical memory (for discussion see $[10,11]$. Locke's memory theory of personal identity claims that specific and accurate memories of past actions and thoughts ensures continuity of personhood over time. Suggesting that mental states, particularly memory states, are essential for continuity of personhood over time is intuitive and has been influential, but there are some well-known conceptual drawbacks of Locke's view having to do with the (1) circularity of memory and identity and (2) the transitivity of memory. I won't repeat those conceptual drawbacks here but see [12].

Here, I want to point out an empirical drawback, namely that Locke's view suggests an archive view on autobiographical memory. On an archive view, specific experiences are stored in discreet and atomistic format. When remembering our personal past, cognitive mechanisms then retrieve memories into consciousness in their exact format and content. However, a wealth of empirical evidence in cognitive psychology going back to Frederic Bartlett [13] makes clear that human memory is not like an archive $^{1}[14-16]$. I get back to this in the next section, but for now I note that human biological memory is not a static archive where atomistic memories can

\footnotetext{
${ }^{1}$ I use the term "biological memory" to refer to memory traces realised in the biological and embodied brain. However, note that whilst remembering can be done without relying on external resources, it is important to point out that our internal and biological memory capacities are shaped by a rich history of interaction with the technological and cultural environment.
} 
provide a reliable and accurate link between two time slices of a person. The content stored in connectionist networks in the embodied brain changes over time, can weaken, and sometimes disappear altogether. Furthermore, autobiographical memories are often condensed versions of experiences and sometimes summarised versions of a number of experiences [16]. We do, of course, have specific memories of past experiences, but - importantly - these are also integrated into an overall narrative structure, implying that autobiographical memory is integrative and holistic rather than discrete and atomistic. Direct memory connections can thus not provide the criterion for continuity of personhood over time.

Schechtman proposes to change the focus from analysing whether we are the same person over time to characterising our identity in the present. The characterisation question asks: "who am I?", rather than "am I the same person over time?" Schechtman's [1] answer to the characterisation question is the narrative self-constitution view. On this view, who we are, our identity, is constituted by our personal narrative ${ }^{2}$. More specifically, "a person's identity (in the sense at issue in the characterisation question) is constituted by the content of her self-narrative, and the traits, actions, and experiences included in it are, by virtue of that inclusion, hers" ([1], p. 94). In order for a narrative to be identity-constituting, she argues, it needs to adhere to three things, namely the narrative needs to be linear and satisfy the articulation and reality constraint. The linearity constraint is important for Schechtman because a human life unfolds chronologically and so the narrative must reflect this. On the articulation constraint, one has to be able to articulate or think through some minimal version of one's narrative. This doesn't mean that one can coherently verbalise or think through one's entire life story or has written an elaborate autobiography. On the reality constraint, which is related to the linearity constraint, our narrative self has to be consistent with reality. If someone's narrative is grossly inaccurate, it cannot be identity-constituting. This doesn't mean the narrative has to be without any inconsistencies. Most people

\footnotetext{
${ }^{2}$ Compare Strawson [104] who denies that narratives are identity-constituting. Instead, Strawson [105] focuses on the minimal subject or the minimal self, which, he argues, should be the focus of debates on self.
}

have some false and inaccurate memories, as human autobiographical memory can be unreliable.

The autobiographical memories building up the narrative are emplotted, which means there are meaningful relations between autobiographical memories [17]. Peter Goldie helpfully writes that "Emplotment brings together the raw material, organising into a coherent whole what is a mere succession of events, actions, objects, individuals, and thoughts, feelings, moods, and emotions. [...] The process of emplotment involves shaping, organising, and colouring the raw material into a narrative structure" ([18], pp. 10-11). Emplotment is thus the process of organising one's memories of experiences into an overall narrative structure. Importantly, without emplotment there can be no real narrative. Summarising, a narrative can be characterised as a subjective, affective, and personal story containing a mostly accurate chronological depiction of a series of connected events and experiences that constitute one aspect of the self and provides continuity of self to some degree. What makes me, me and what differentiates me from other persons is my narrative. It provides a sense of personal continuity and allows us to see our lives as an unfolding project in which there is continuity of one's interests, traits, values, and life themes ${ }^{3}$.

Cognitive psychologists distinghuis between episodic and semantic memory [19]. Episodic memories are memories of personal experiences such as eating a Thai curry, giving a lecture, or going on a citytrip to Barcelona. When we episodically remember those experiences, we mentally travel back in time, as it were, and perceptually re-experience the event. Doing so has a distinct phenomenology: it is something-itis-like to episodically remember our past experiences. Semantic memories - by contrast - are propositional in content. These include facts about domains like politics, biology, or archaeology. Importantly, they also include facts about our personal past, for example

\footnotetext{
${ }^{3}$ Our narrative identity is part of a larger identity system that also includes cultural identity. Cultural identity can be characterised as the membership to a cultural group such as a nation, religion, political group, generation, or family [106]. Cultural identity is not an intrinsic property of persons, but is a relational social property, as it is developed and maintained in relation to cultural groups. Narrative and cultural identity interact in various ways building up a larger identity system [107].
} 
remembering (or knowing) that we graduated from high school but not being able to re-experience that event. The distinction is about the content of the memories being experiential versus propositional. These types of memories are realised by different systems in the brain [20]. One can have damage to one system but not the other. Significantly, the building blocks of our narrative include both episodic and semantic memories. Episodic and semantic memories of the personal past are often subsumed under the more general notion of autobiographical memory.

Research in cognitive psychology shows that narratives often have a specific shape. To better understand this shape, I briefly introduce the concepts of "cultural life script" and "reminiscence bump". Berntsen and Rubin [21] argue that most life stories are consistent with a cultural life script. Metaphorically, our life can be seen in terms of "chapters" such as childhood, adolescence, going to university, first job, marriage, having children, buying one's first house, having grandchildren, retirement, etc. Also, transitions between these chapters are typically expected to happen on certain times. It's often seen as unusual if someone graduates from university at age 65 or gets pregnant at age 15. Certainly, not all lives fit this cultural template, but most lives are more or less consistent with cultural life scripts.

Finally, the lifespan retrieval curve is a graph in which the number of autobiographical memories people can recall is plotted against the time in years. It turns out that this curve has a unique shape. Most people have trouble remembering events before age 10 , which is referred to as childhood amnesia. In adolescence and early adulthood, roughly between 10 and 30 years of age, there is a bump in the graph's line, called the "reminiscence bump" in which people can recall many experiences and events. The peak of this reminiscence bump is around 20 years of age. During this phase in our life, we often have many identity-shaping experiences. We graduate from high school and go to university, go on holiday without our parents for the first time, make new (and often lasting) friendships, have our first romantic relationships, move out of our parental home, have our first job, etc. Such experiences shape who we are in important ways. Clearly, we continue to have identity-shaping experiences throughout our lives, but such experiences are particularly frequent in our late teens and twenties. Memories from that period are more accurate, are judged to be more significant than memories from other periods, and are rated as highly likely to be included in one's narrative [22]. So, narratives have chapters which are more or less consistent with a cultural template and there is a particularly important chapter in our late teens and twenties.

\section{Distributed Memory}

In the previous section, I argued that, on one level of analysis, human identity has a narrative structure constituted by emplotted autobiographical memories, including those with episodic and semantic content. In this section, I argue that such memories are not brain-bound but are sometimes extended and distributed across an embodied agent and environmental resources.

The view that human memory systems are interwoven with information in the environment was first given a systematic statement by Donald [23] and is becoming increasingly prevalent Hutchins [24-28]. The theories of the extended mind [29], transactive memory Wegner [30, 31], and distributed cognition Hutchins [24] argue that memory systems are emergent systems, resulting from the embodied interactions between humans and their material and social environment. Under certain circumstances, human biological memory systems and external resources are integrated into distributed memory systems [6, 27, 32]. Ontologically, when our biological memory systems and external resources are appropriately integrated, they constitute one memory system in which the external resource is literally part of the system that remembers. Heersmink [33] has conceptualised the degree of integration between our biological memory systems and external resources in terms of a number of dimensions. These dimensions include the type of information flow, accessibility of the resource, durability of the relation between agent and artifact, trustworthiness of the information the artifact contains, procedural transparency or ease of use, informational transparency, the degree of personalisation, and the autobiographical dependency. When the relation between an embodied agent and an external resource ranks high on these dimensions, the two components are deeply integrated and the more likely it is that they form a distributed cognitive system. 
Turkle [5] proposes the notion of an "evocative object", which are objects that are associated with experiences in one's personal past. A photo album reminds you of that city trip to Barcelona, a biology textbook on your bookshelf reminds you of a friend you met in college, your diploma reminds you of your graduation, your favourite chair reminds you of a film you saw, a toy reminds you of your child, and so on. We often remember our past by interacting with artifacts. The total field of evocative objects has been referred to as an "autotopography", that is, a material topography of the self. Philosopher Jennifer Gonzalez characterises an autotopography as follows:

"A private-yet-material memory landscape made up of the intimate expressions of values and beliefs, emotions and desires, found in the domestic collection of objects. [...] It's a careful, visual arrangement of mementos and heirlooms, on the one hand, and a jumbled, hidden assembly of dusty and unkempt objects, on the other, both can constitute a material memory landscape" (1995, p. 133).

The experiences and events in our personal past are materialised in the objects we keep in our lifeworld. Our autotopography is like an autobiography, but rather than using language as a medium to express and store our memories we use material objects. Our autotopography has a fluid composition, as we frequently remove items from it and add items to it [34]. As we move through life, we forget some memories but add new ones to our narrative. This changing narrative is reflected in the composition of our autotopography. Autotopographies thus co-evolve with their user's narrative identity.

Recently, new types of evocative objects are emerging referred to as lifelogging or self-tracking technologies [35]. These are digital technologies, allowing their user to record aspects of their past. SenseCams, for example, are small wearable cameras that you wear around your neck or clip on your shirt. These are popular lifelogging technologies and are used by both cognitively healthy persons and by those with memory disorders, including dementia, amnesia, or brain injury [36]. SenseCams take a picture when their internal sensors record a change in environmental conditions like GPS location or light intensity, resulting a visual narrative of one's daily activities. Lifelogging goes much further than merely storing photos of past activities. Lifelogs can also contain one's GPS locations, internet browsing behaviour, emails, dietary intake, descriptions of activities, and much more.

Heersmink [6] argues that autobiographical memory is extended and distributed across embodied agents interacting with evocative objects. Such objects do not merely trigger the retrieval of internally stored memories but contribute to constructing a memory by providing information that is no longer available in the embodied brain. Biological memory is not like a static archive where memories are stored atomistically and discretely. Instead, memories are stored in connectionist networks in which the connection weights between the nodes that store the content of the memory weaken over time [15, 37]. A brief note on how I intend to use the word "store" will be helpful. With "storing" I do not mean that information in biological memory traces is fixed, and it certainly is not stored in the same way a computer stores information. But information is nonetheless retained in connectionist networks (compare [38], [39]).

A crucial point here is that because of the changing content of biological memories, we need the informational stability provided by evocative objects to reliably remember our past. Photographs, for example, can provide information about personal experiences that is no longer stored in the brain or only partially stored in the brain [40]. When interacting with photographs we integrate information in the embodied brain and in the photograph to construct a fuller, more detailed memory. In such cases, an evocative object does much more than merely trigger a fully formed memory. Instead, the information it contains helps to construct a memory in a way that is not possible without the object. In this sense, the information we use to remember our personal past is distributed across embodied brains and the environment. Information external to the embodied brain can thus play constitutive roles in our narrative identity (see also [41]).

\section{Dementia and Narrative Identity}

Having introduced the notions of narrative identity and distributed memory, I now move on to characterise dementia and its effect on narrative identity. Dementia is a category of brain diseases, causing a long-term, gradual decrease in the capacity to think 
and remember. Ultimately, it effects most cognitive capacities such as planning, navigating, calculating, learning, language use, and remembering. It's often accompanied with affective states like anger, frustration, and depression, severely impacting a patient's sense of well-being. There are various kinds of dementia, including Alzheimer's disease, vascular dementia, dementia with Lewy bodies, frontotemporal dementia, Huntington's disease, Korsakoff's syndrome, and Creutzfeldt-Jakob disease. The two most common types of dementia are Alzheimer's disease and vascular dementia, constituting $70-85 \%$ of all cases. At this point in time, the causes of dementia are not yet well-understood and there is no known cure for it. However, to a certain extent, one can delay the onset of dementia with an active lifestyle, healthy diet, social interactions, intellectual stimulation, and not smoking and drinking. The World Health Organisation estimates that in 2019 more than 50 million people have dementia worldwide and each year there are nearly 10 million new cases. Because the world's population is increasing and people are getting older, the total number of people with dementia is projected to reach 82 million in 2030 and 152 million in 2050. Dementia creates major existential, emotional, social, and economic costs, particularly for the patients but also for caregivers, family, and society at large.

The symptoms associated with dementia develop progressively and can be divided in three stages $[42]^{4}$. Early-stage dementia is charactered by general forgetfulness, losing track of the time, and becoming lost in familiar places like one's own neighbourhood. Sometimes people are diagnosed with mild cognitive impairment before they are diagnosed with early-stage dementia. Middle-stage dementia is characterised by becoming forgetful of recent events and people's names, having increasing difficulty with communication, experiencing behaviour changes such as wandering and asking repeated questions. Patients in this stage also need help in their personal care, either at home or in a nursing home. Late-stage dementia is characterised by becoming unaware of the time and place, having difficulty recognizing

\footnotetext{
${ }^{4}$ Some psychiatrists and neurologists identify seven stages in the development of dementia ranging from appearing normal, very mild, mild, moderate, moderately severe, severe, very severe.
}

family and friends, having difficulty walking, and experiencing behavioural changes that may escalate and include aggression. Patients in this stage are completely dependent on care, are typically inactive, chronically confused, and clinically depressed. These three stages are, of course, broad brush characterisations of the development of dementia and not all types of dementia are characterised by these symptoms.

People in early-stage dementia typically experience a relatively minor change in their narrative identity. Caddell and Clare [43] found that such patients describe both continuities and discontinuities with their past self. They are usually still living at home with their partners and can, for the most part, still do the things they enjoy doing. Their political and religious views, preferences, and personality are still largely the same. One discontinuity has to do with their activities, particularly conversations with others are different due their slowly decreasing memory capacities, forgetting names and events. Participants are aware that this will continue and progress in the future. Caddell \& Clare point out that "Several participants made a link between a potential worsening of their memory ability and a change in an aspect of their identity" ([43], p. 395). Addis and Tippett [44] investigated the effects of Alzheimer's disease on the autobiographical memory and narrative identity of twenty early-stage and middle-stage patients. They found that Alzheimer's disease reduces the number of autobiographical memories, both episodic and semantic. Their descriptions of past experiences were fewer in number and more abstract, vaguer, and less definite. Mills [45] reports a similar effect, but her works also shows that talking about their past with an interviewer can reduce anxiety and increase the sense of wellbeing of Alzheimer's patients.

One of the earliest characteristics of Alzheimer's disease is anterograde amnesia, which is an inability to form and consolidate new memories. This is followed by retrograde amnesia, which is an inability to retrieve older memories. So, patients first have trouble consolidating new memories and then, when the disease progresses, also have trouble accessing existing memories. Alzheimer's disease is characterised by a substantial shift from episodic to semantic remembering [46]. The neuropathological processes of Alzheimer's disease first affect the brain systems realising episodic memories. This gradual loss of episodic memories leads to the semanticization of 
autobiographical memories, in that when remembering their past Alzheimer's patients tend to rely on propositional information about their past, remembering that something happened to them but not being able to visually relive the events [47]. Episodic memories of previously self-defining experiences such as one's wedding day, birth of a child, or death of a parent are reduced to semanticised accounts of those events [48].

Patients in early-stage and middle-stage Alzheimer's can thus still semantically remember some of their past. However, as the disease progresses the brain systems realising semantic memories are also affected and such memories will eventually also become lost. So, due to anterograde amnesia, retrograde amnesia, and the semanticization of autobiographical memories, Alzheimer's patients have limited access to the memories that build up their narrative identity. This suggests that their narrative becomes increasingly impoverished. As written above, a person's narrative contains autobiographical memories with both episodic and semantic content. As the disease progresses, patients first lose the capacity to form new episodic memories, older episodic memories are then also lost, and finally semantic memories of the personal past are lost.

Surr [49] shows that most of the fourteen middlestage and late-stage Alzheimer patients she interviewed still have some sort of narrative identity. They can still tell reasonably coherent stories about their past, linking two or more events in a narrative structure. Likewise, Mills [45, 50] found that the eight Alzheimer patients she interviewed still have some sort of narrative. It is, however, fragmented, events are not always represented in chronological order, essential life events are missing, and there is usually repetition in how they tell their life story. Researchers found that the loss of autobiographical memories and the disintegration of narrative identity causes a significant decrease in the sense of well-being. This decrease in well-being was specifically related to a loss of memory and narrative identity, not to their general cognitive decline. Researchers found that "amongst those suffering from dementia, loss of memory serves to compromise well-being primarily because it is associated with loss of identity ([45, 50], p. 408). Not being able to remember the personal past is very frustrating for patients and significantly decreases their well-being.
Neurologist Sacks [2] describes a patient with Korsakoff's syndrome, a type of dementia caused by excessive consumption of alcohol. Due to his excessive drinking, Mr. Thompson can no longer remember large parts of his narrative. He has some autobiographical memories, but these are not meaningfully connected in any way. To make sense of situations, he confabulates micro-narratives on the spot. For example, because Sacks wears a white coat, he infers Sacks is a butcher and so he must be a customer in a butcher's shop. He says: "No blood stains on your coat though. Business bad today? You'll look like a slaughterhouse by the end of the week" ([2], p 103). Had he not lost his narrative, he would have remembered who Sacks is and would not have to resort to confabulation. Sacks recognises how crucial narratives are for identity, claiming that:

"To be ourselves we must have ourselves posses, if need be re-possess, our life-stories. We must 'recollect' ourselves, recollect the inner drama, the narrative, of ourselves. A man needs such a narrative, a continuous inner narrative, to maintain his identity, his self" ([2], pp. 105-106, original italics).

Because Mr. Thompson lost his narrative, "he was continually creating a world and self, to replace what was continually forgotten and lost" (1985, p. 105). These world-making and self-making processes created in Mr. Thompson what Sacks refers to as "narrational frenzy", desperately trying to understand his identity in relation to situations. On Schechtman's narrative self-constitution view, "the limits of a person are determined by the limits of a narrative, and the integrity of a single person consists in the unity of a narrative" ([51], p. 336). Thus, if dementia disintegrates a person's personal narrative, then it also disintegrates one's narrative self, which is what happened in Mr. Thompson and other dementia patients in advanced stages of the disease. In the next section, I propose a number of ways to deal with this disintegration of narrative identity.

To which extent the minimal self (or subject of experience) is affected by dementia is less clear. The minimal self is the entity that has an experience, characterised by a subjective, first-personal perspective on the world $[52,53]$. The sorts of experiences a minimal self has are of a pre-reflective, pre-linguistic, and pre-conceptual kind. They are experiences of raw, 
unprocessed percepts or affects. To better understand the minimal self, we must study the structure of experience, focusing on the what-it-is-likeness of pure subjective experience. Late-stage dementia patients may have lost most of their narrative self, but (presumably) still have the capacity for subjective experience. It is something-it-is-like to be a patient with late-stage dementia or severe Korsakoff's syndrome. A minimal self thus remains throughout the course of the disease [54-56]. It does, however, change what it is like to be a person with dementia throughout the course of the disease [57]. The way in which the world is experienced, the subjectivity of the patient, will significantly change throughout the course of the disease [58].

Embodiment plays an important role in both the minimal self and the narrative self of dementia patients. The minimal self is instantiated in the brain and neuromuscular systems - including its capability for perception, proprioception, and action - it is therefore an embodied self [59]. As said, this embodied minimal self remains throughout the course of the disease and some scholars have suggested that person-centred care should focus on embodied activities such as drama, art, dance, and massage therapy [60]. Importantly, narratives, too, are the result of our embodied experiences [61-63]. Menary [64] argues that our narratives are anchored in our embodiment, in that our narratives arise directly from our lived experience as embodied subjects. Some of the firstpersonal embodied experiences of a minimal self can become episodic memories that are integrated into the narrative. Embodiment is thus central to both minimal and narrative selfhood.

Philosopher and psychiatrist Hughes [65, 66] distinguishes two views of the person with dementia. One is based on a Lockean [9] and Parfit [8] view. As we have seen above, Locke argues that persons are continuous over time only when they can remember specific experiences. On a Lockean view, direct memory connections thus establish continuity of personhood over time. Derek Parfit cats his net wider and focusses on overlapping chains of mental states, including memories, intentions, beliefs, and desires. On this view, we are psychologically connected to our past self when there are sufficient overlapping chains of mental states. Hughes rejects these views because they do not recognise the embodiment and embeddedness of people with dementia. Locke and Parfit's views are overly reductive and internalist, only focussing on brain-based mental states and their links to the past. Hughes suggests an alternative, namely "the situated-embodied-agent view", according to which, "the person is best thought of as a human agent, a being of this embodied kind, who acts and interacts in a cultural and historical context in which he or she is embedded" ([65], p. 87). The key notions for Hughes are active agency, embodiment, and situatedness.

I am very sympathetic to Hughes' situated and embodied agent view: it is conceptually and empirically a more accurate and plausible view than the internalist and reductionist views of Locke and Parfit. However, I do not think Hughes goes far enough. As argued above, autobiographical memories (and other cognitive states and processes) are not merely situated and embedded, as Hughes has it, but sometimes properly extended and distributed across the embodied agent and environmental resources [6]. Hughes' view is an important step in the right direction but is ultimately still individualist and internalist. Recognising the externalist and distributed nature of memory and narrative identity, suggests a stronger obligation towards dementia patients to ensure their memories and identity are distributed in a way that preserves their memory and narrative identity.

Daniel Dennett points out that taking dementia patients "out of their homes is literally separating them from large parts of their minds, potentially just as devastating a development as undergoing brain surgery" ([67], p. 138). Dennett here argues that there is an equivalence between information stored in biological memory and information stored in the environment in terms of the role that information plays for the person. So, deleting memories from one's brain has potentially the same effects as removing artifacts from one's autotopography if those brainbased memories and artifacts play the same roles for the person. This equivalence implies information external to the biological organism can have the same ontological and cognitive status as information stored in one's embodied brain. The cognitive status of external information, in turn, implies a moral status $[68-70,71)$. If external information can play the same functional roles as information in biological memory in preserving the narrative identity of a dementia patient, then we ought not to intervene in the environment of such patients in a way that diminishes their narrative identity. Because of the moral status 
of some evocative objects, we have a strong motivation towards these patients to help them in preserving their distributed memories and narrative identity.

\section{Strategies for Dealing With Memory and Identity Loss}

Given the importance of memory and narrative for one's identity, the central healthcare question is this: How to organise the environment of dementia patients as to help them preserve their memory and narrative identity? In this section, I propose several strategies in structuring the autotopography of dementia patients as to maintain their autobiographical memories and narrative identity (see also [72]. I believe a person-centred and personalised approach is essential for dementia patients as to increase their well-being. Objects evoking and distributing autobiographical memory can improve the well-being of people with dementia, in that they can help to maintain the integrity, delay the disintegration, or in some cases replace parts of one's personal narrative. Some of these suggestions presented below are based on existing empirical research, whereas others are more speculative. Dementia patients still living at home have carefully structured their environment in a way that supports their autobiographical memories and their narrative identity. Transferring them to a nursing home often causes a tragic moment in the development of the disease. For this reason, such patients should preferably stay at home for as long as possible. And when they do have to go to a nursing home, they should be able to reconstruct their autotopography in the nursing home as much as is practically possible. Below I present some ways to do this.

Recall that Alzheimer's patients first lose the capacity to form new episodic memories (anterograde amnesia), then older episodic memories are also lost (retrograde amnesia), and finally semantic memories of the personal past are lost. SenseCams are very promising memory aids to help deal with anterograde amnesia $[36,73]^{5}$. Viewing SenseCam images

\footnotetext{
${ }^{5}$ Note that storing doesn't mean that the content of the memory trace is fixed and archive-like. On a connectionist view, one can still say that autobiographical memories are stored in the embodied brain without being committed to the archive or storehouse model. Using the word "store" in relation to autobiographical memory doesn't necessarily mean that the content of memories is unchanging. We can still say that memories are stored, just not in discrete and atomistic format, rather they are stored in a dynamic and integrative manner.
}

of recent events allows for a stronger consolidation of the content of the memory in a biological memory trace. Up to six months after reviewing the images, patients had a better recall of the events compared to events that they had written in a diary. The visual nature of images is thus more effective in aiding the consolidation of memories compared to written language [74]. Cognitive psychologists distinguish between three types of memory processes, namely encoding, storing, and retrieving [75]. Encoding is the initial process of perceptual learning of an event, storing is maintaining information over time [76], and retrieving has to do with accessing the information when you need it. Neuropathological processes related to dementia can influence these processes, causing them to malfunction. Sometimes the encoding and storing of an experience still works, but the retrieval processes do not.

In addition to aiding the consolidation of a memory in the embodied brain, SenseCam images can trigger the retrieval of memories that are otherwise inaccessible, in that way aiding in dealing with retrograde amnesia [77]. SenseCam images have this causal efficacy because they are cognitively comparable with biological episodic memory in that "they are visual, represent short time slices of experience, they are time compressed and fragmentary, they are formed outside intentional awareness, they preserve the perspective of the individual at the time of the event, and they are temporarily ordered" ([77], pp. 701-702). Pattern recognition mechanisms comparing new perceptual input with stored information in biological memory can trigger the retrieval of otherwise inaccessible episodic memories. However, if the information is not stored or no longer stored, then even a SenseCam image cannot trigger its retrieval.

Dementia patients in the early and middle stages of the disease often use a "memory book" to aid them in remembering both semantic and episodic memories. Andy Clark and David Chalmers' (1998) extended mind view was motivated with a hypothetical example of a man with early Alzheimer's disease, using a notebook to remember semantic memories such as, for example, an address. There is a rich body of literature in psychology and gerontology examining how dementia patients use such memory books (e.g., [78]. Such general memory books typically include semantic information about, for example, to-do lists, phone numbers, etc. 
A more specific type of memory book is the "life story book" [79]. These are books that include various sorts of evocative objects such as photographs, postcards, concert tickets, narrative descriptions of personal experiences, quotations, news items, and other items with autobiographical relevance. These items are organised chronologically, reflecting a person's life story. In some cases, only the patient him or herself composes the content of the life story books, in other cases both the patient and partner or caregiver are involved in the process of creating the life story book. The emplotment and creating the storyline is thus sometimes done by the patient and sometimes by both the patient and a caregiver. Researchers found that creating a life story book together improves the relationship between the patent and caregiver [79]. In a meta-analysis, researchers found that life story books consistently created a significant improvement in autobiographical memory, mood, depression, and sense of well-being [80].

For some patients, the (process of making a) life story book has remarkable consequences. Mary, an 80 -year-old lady with moderate dementia, created a life story book consisting of her wedding album, wedding invitation card, and telegrams from relatives and friends, which brought back many positive memories. In particular, creating and using a life story book triggered many happy memories about her husband who died early in their marriage. When the researchers showed Mary's sister the life story book, she replied: "She (Mary) told all this to you (referring to quotations from life review sessions). Hard for me to believe...I thought she can't remember all this. This is something great" ([79], p. 372).

Similarly, researchers in Canada developed what they refer to as a "multimedia biography" for people with mild cognitive impairment or Alzheimer's disease [81-83]. These multimedia biographies are a video compilation of various evocative objects such as photos, letters, documents, home videos, music, and narration. The video has several acts representing life stages such as adolescence, marriage, career, and hobbies, which are told chronologically. This approach is consistent with the notion of "cultural life script" presented above, arguing that human lives and narratives have consecutive stages or chapters [83]. An advantage of multimedia biographies as compared to life story books is that they allow to include music, which is particularly helpful in evoking autobiographical memories [84]. The researchers point out that: "family members and participants perceived the multimedia biographies as a means for preserving the personhood of their loved one" [85], p. 101, italics added), suggesting that self-defining memories can be materialised in multimedia biographies which help to preserve the personhood of the patient. Importantly, life story books and multimedia biographies do not just aid their users in remembering one specific event but contain a variety of evocative objects. Their function is to support parts of the narrative of the patients, which are emplotted chronologically. So, these aren't mere memory aids but proper narrative aids.

Another strategy has to do with what Gulwadi [86] refers to as "self-memory boxes", which are transparent display cabinets with evocative objects. Gulwadi reports on her empirical work in three dementia care facilities where wall-mounted display cabinets are located right next to the entrance of a resident's room. The evocative objects displayed in these self-memory boxes include pictures of family members, certificates, mementos, pictures with colleagues, religious items, items representing one's country or ethnic background, artworks (e.g., a painting), and crafts (e.g., quilts, embroidery). Self-memory boxes have various functions, the most obvious one being reminiscing about the past. Gulwadi points out that "the memory boxes and their contents act as catalysts for the creation and re-creation of identity" ([86], p. 117). Another function is that they allow staff to form a picture of the narrative identity of residents. Rather than seeing them as mere frail patients, the evocative objects (e.g., travel cards, family photos, certificates) allows staff to get a sense of the past of a resident.

Researchers in Denmark designed a reminisce therapy in which dementia patients are immersed in a holistic and historically authentic environment called the "House of Memories" [87, 88]. The House of Memories is an exact replicate of a Danish 1950s apartment, including a variety of evocative objects from the 1950s such as utensils, clothing, furniture, art, etc. The participants are encouraged to interact with the objects, sometimes re-enacting activities such as setting the table with tablecloth and porcelain. Most of the dementia patients are in their 70s and 80s and so they were in their teens and twenties when they were living through the 1950s. This is important because they were living through their reminiscence bump, which is a particularly crucial "chapter" in one's life story. Research suggests that memories 
of home are important to people with dementia [89]. The generic evocative objects in the House of Memories aid patients in reconstructing autobiographical memories of experiences had in one's home. Researchers found that "providing retrieval support, in terms of naturalistic historical cues, allows participants to retrieve more specific and detailed memories from their past" ([87], p.1080). If generic evocative objects already have this effect, it is very likely that their own unique evocative objects will have a stronger and more targeted effect.

It is important to note that some of the abovedescribed artifacts do not merely aid dementia patients in remembering their past, in that they do not trigger the retrieval of a fully formed biological memory. Rather, what often happens is that information in a biological memory trace and information stored in an artifact is integrated into a memory. So, the information the conscious self uses to remember its past is distributed across embodied agent and the environment [90, 91]. Often, the deeper a memory is in our past, the more likely it is that the memory trace has weakened, in which case episodic information is faint. The information in an artifact, for example a photo or video, may then be used to form a fuller, more detailed episodic memory. The information in the artifact then supplements the information in the brain. When the biological memory trace has completely decayed, (SenseCam) images may only trigger semantic memories about past experiences. Whilst episodic memories play important roles in one's narrative identity, semantic memories about the personal past are still useful in preserving one's narrative identity. As written above, because of the semanticization of autobiographical memories, dementia patients have more intact semantic memories. Semantic autobiographical memory supports knowledge of one's traits, roles, thoughts, beliefs, desires, and feelings. It may therefore support self-referential thinking such as reflecting on one's past, imagining a personal future, and preserving a narrative identity [47]. Retrieving and constructing semantic memories about the personal past is thus an important activity for patients who may no longer have episodic memories.

Evocative objects can have both representational and non-representational properties. Photos, videos, and drawings represent autobiographical information through a visual resemblance with an event/experience, whereas furniture, clothing, and jewellery do not visually resemble an event/experience. Rather, such objects obtain autobiographical significance through a learned association between the object and an event/experience. Evocative objects with visual representational properties tend to evoke more episodic memories, whereas objects with non-representational properties tend to evoke more semantic personal memories [92]. So, in the early and middle stages of the disease when episodic memory is still relatively intact, visual representational objects may aid patients in accessing or constructing episodic memories. In the later stages of the disease when episodic memory capacities are completely gone, visual representational objects can still be used - but will no longer be efficacious to access or construct episodic memories - rather they will merely aid in retrieving semantic memories of the personal past. Evocative objects with non-representational properties can be used throughout the disease to aid in retrieving semantic memories of the personal past, until the learned association between the object and an event/ experience has decayed.

Up to now, I have discussed various existing strategies for supporting the autobiographical memories of dementia patients. I will now speculate on strategies based on emerging technologies such as ambient intelligence. Ambient intelligence is a design paradigm in computer science and artificial intelligence, referring to electronic environments that are sensitive and responsive to the presence of people and their specific needs. Aarts [93], pioneer in ambient intelligence research, points out that such systems are characterised by the following five properties. Ambient intelligent systems are:

- Embedded: many networked devices and sensors are integrated into the environment.

- Context aware: these devices can recognise you and your situational context.

- Personalised: they can be tailored to your needs.

- Adaptive: they can change in response to you.

- Anticipatory: they can anticipate your desires without conscious mediation.

Such systems use sensors to monitor human behaviour to infer one's needs and desires. Perhaps we can make the environment of dementia patients more intelligent and responsive to their individual needs [94]. One might imagine a future where sensors 
are embedded in a patient's bed, bath, toilet, clothing, refrigerator, TV, computer, and medicine box, as to infer the patient's heart rate, sleeping patterns, eating patterns, metabolism, location inside and outside the home, information consumption, mood, and level of well-being. Based on this information, the system can create a personalised cognitive and behavioural profile, allowing the system to detect anomalies in behaviour. This profile can be supplemented with information about the patient's past supplied by the patient him or herself, family members, and other caregivers. If the patient had or has social media profiles, information can be extracted from that, too. This information can be compiled into a biography of the patient, supported with evocative objects such as photos, videos, music, and narration. When the patient has low mood, the system may detect this in behavioral changes and play memory-evoking music, show photos of positive past experiences, or play narration from a partner or family member. The system can monitor how the patient responds to these evocative objects and learn which evocative objects are most effective in which situations.

One possible moral issue with this sort of ambient intelligent monitoring system has to do with informational privacy and data protection [95-97]. Informational privacy is an important moral value and can be defined as the interest of individuals in exercising control over access to information about themselves [98]. Possible infringements of privacy are particularly pertinent in this context, as one's home environment is experienced as a safe place where one feels trust, comfort, and private. Dementia patients are particularly vulnerable as their cognitive impairment may not allow them to fully control the system's settings. It's therefore essential that ambient intelligent systems are designed such that the informational privacy of their user is safeguarded. The moral value of informational privacy should be designed into the algorithmic and physical architecture of the system, ensuring sensitive personal data to be protected. It's also important that the patient and/or caregiver(s) are informed about the possible privacy risks of the system and give their consent before the system is used.

We know that animal companion robots have a positive effect on the well-being of dementia patients [99]. A specific example is Paro, a baby harp seal designed as a therapeutic robot for use with older people, particularly those with dementia [100].
Interacting with Paro reduces stress levels and stimulates interaction between patients and caregivers. Maybe we can design humanoid companion robots with conversational abilities [101] and embed these as part of the ecosystem, allowing the patient and robot to reminisce about particular experiences, events, or episodes from the patient's past. If this seems farfetched to some readers, think of the movie Blade Runner 2049, in which a companion robot in the form of a hologram plays a similar sort of role [102]. Joi (a hologram) and officer K share experiences and talk about those shared experiences during reminiscing.

Even further into the future, perhaps we can immerse dementia patients in virtual reality (VR) simulations of their memories. Recent episodic memories are often experienced through an internal, first-personal perspective where we see the event unfolding through our own eyes. Older episodic memories are often experienced from an external, third-personal perspective where we see ourselves in the event [103]. Depending on the memory and its location in the narrative, maybe we can build VR simulations of self-defining events from both a first-personal and third-personal perspective before the dementia decays those memory traces. The immersive dimension of VR may help in reliving the experience and perhaps (insofar as this is still possible) in reconsolidating the experience in memory. So, rather than triggering an internal memory, perhaps we can recreate the original event in a VR environment, allowing the patient to "relive" the original experience.

A somewhat similar approach has been suggested in Germany, where researchers designed a VR environment of a famous street in the town of Krefeld in the $1950 \mathrm{~s}$ and $1960 \mathrm{~s}^{6}$. With the help of historical photographs from the city archives and personal recordings from numerous inhabitants of Krefeld, the street scene was created in an interactive VR format, containing buildings, cars, busses, trams, and people in 1950s and 1960s clothing. This has been used by dementia patients at the local hospital to experience a street they had spent time in during their youth and adolescence, which is when they had their reminiscence bump. The chief geriatrician reports that the initial findings of the project were positive. In some ways, this project resembles the House of Memories

\footnotetext{
${ }^{6}$ https://www.helios-gesundheit.de/kliniken/huels/unser-haus/ aktuelles/detail/news/demenz-patienten-reisen-mit-virtual-reali ty-technologie-in-die-vergangenheit/
} 
in Denmark, in that in contains a generic evocative object from a period in which the patients had their reminisce bump. Importantly, it shows that VR technology can be used to recreate generic events from the past. Perhaps in the near-future, it may be possible to recreate more person-specific events in VR and to use those to allow patients to relive their past experiences.

\section{Conclusion}

This paper has first conceptualised the relation between narrative identity and the environment in which we are situated, arguing that the narratives of both cognitive healthy agents and those with dementia are distributed across embodied agents interacting with evocative objects. The paper ended with suggesting several strategies, some old, some new, to help support and distribute the autobiographical memories of dementia patients and possibly delay the disintegration of the narrative identities of such patients. Given that the loss of memory and narrative identity has a negative effect on well-being, using evocative objects to help maintain the integrity, delay the disintegration, or in some cases replace parts of one's personal narrative is a very promising way to improve the well-being of dementia patients. However, none of the strategies I discussed are miracle cures for the way dementia erodes memory and narrative identity, the nature of the disease is such that one type of intervention will not solve all problems, but taken together, they may aid some patients in preserving their narrative identity in a way that would not be possible when merely relying on their biological memory. Recognising the distributed nature of memory and narrative identity, invites us to find treatments or strategies focusing on the environment in which dementia patients are situated. Rather than thinking of dementia as a disease solely concerned with the brain, we should recognise that dementia is also concerned with the relation these patients have to their environment, to their autotopographies.

Funding Open Access funding enabled and organized by CAUL and its Member Institutions.

\section{Declarations}

Conflicts of Interests/Competing Interests I declare there are no conflict of Interests or competing Interests.
Open Access This article is licensed under a Creative Commons Attribution 4.0 International License, which permits use, sharing, adaptation, distribution and reproduction in any medium or format, as long as you give appropriate credit to the original author(s) and the source, provide a link to the Creative Commons licence, and indicate if changes were made. The images or other third party material in this article are included in the article's Creative Commons licence, unless indicated otherwise in a credit line to the material. If material is not included in the article's Creative Commons licence and your intended use is not permitted by statutory regulation or exceeds the permitted use, you will need to obtain permission directly from the copyright holder. To view a copy of this licence, visit http://creativecommons.org/licenses/by/4.0/.

\section{References}

1. Schechtman, M. 1996. The constitution of selves. Ithaca: Cornell University Press.

2. Sacks, O. 1985. The man who mistook his wife for a hat and other clinical tales. London: Summit Books.

3. Jetten, J., C. Haslam, C. Pugliese, J. Toks, and A. Haslam. 2010. Declining autobiographical memory and the loss of identity: Effects on well-being. Journal of Clinical and Experimental Neuropsychology 32 (4): 408-416.

4. Buse, C., and J. Twigg. 2016. Materialising memories: exploring the stories of people with dementia through dress. Aging \& Society 36 (6): 1115-1135.

5. Turkle, S., ed. 2007. Evocative objects: Things we think with. Cambridge: MIT Press.

6. Heersmink, R. 2020a. Extended mind and artifactual autobiographical memory. Mind and Language. https:// doi.org/10.1111/mila.12353.

7. Olson, E.T. 1997. The human animal: Personal identity without psychology. New York: Oxford University Press.

8. Parfit, D. 1984. Reasons and persons. Oxford: Oxford University Press.

9. Locke, J. (1979/1694). An essay concerning human understanding. Oxford: Clarendon Press.

10. Schechtman, M. 2005. Personal identity and the past. Philosophy, Psychiatry and Psychology 12 (1): 9-22.

11. Weinberg, S. 2011. Locke on personal identity. Philosophy. Compass 6 (6): 398-407.

12. Gordon-Roth, J. (2019). Locke on personal identity. In E. Zalta (ed.), Stanford Encyclopedia of Philosophy. URL: https://plato.stanford.edu/entries/locke-personal-identity/

13. Bartlett, F. 1932. Remembering: A study in experimental and social psychology. Cambridge: Cambridge University Press.

14. Schechtman, M. 1994. The truth about memory. Philosophical Psychology 7 (1): 3-18.

15. Sutton, J. 2009. Remembering. In The Cambridge handbook of situated cognition, ed. P. Robbins and M. Aydede, 217-235. Cambridge: Cambridge University Press.

16. Brockmeier, J. 2015. Beyond the archive: Memory, narrative, and the autobiographical process. Oxford: Oxford University Press. 
17. Ricoeur, P. (2004). Memory, history, forgetting. Translated by K. Blamey \& D. Pellauer. Chicago: University of Chicago Press.

18. Goldie, P. 2012. The mess inside: Narrative, emotion, and the mind. Oxford: Oxford University Press.

19. Tulving, E. 1972. Episodic and semantic memory. In Organization of memory, ed. E. Tulving and W. Donaldson, 382-404. New York: Academic Press.

20. Squire, L.R. 2009. Memory and brain systems: 1969-2009. The Journal of Neuroscience 29 (41): 12711-12716.

21. Berntsen, D., and D. Rubin. (2004). Cultural life scripts structure recall from autobiographical memory. Memory \& Cognition 32 (3): 427-442.

22. Rathbone, C., C. Moulin, and M. Conway. 2008. Selfcentered memories: The reminiscence bump and the self. Memory \& Cognition 36: 1403-1414.

23. Donald, M. 1991. Origins of the modern mind: Three stages in the evolution of culture and cognition. Cambridge: Harvard University Press.

24. Hutchins, E. (1995). Cognition in the wild. Cambridge: MIT Press.

25. Rowlands, M. 1999. The body in mind: Understanding cognitive processes. Cambridge: Cambridge University Press.

26. Clark, A. 2005. Intrinsic content, active memory, and the extended mind. Analysis 65 (1): 1-11.

27. Sutton, J. 2010. Exograms and interdisciplinarity: History, the extended mind, and the civilizing process. In The extended mind, ed. R. Menary, 189-225. Cambridge: MIT Press.

28. Clowes, R. 2017. Extended memory. In Routledge handbook of the philosophy of memory, ed. S. Bernecker and K. Michaelian, 243-255. London: Routledge.

29. Clark, A., and D. Chalmers. 1998. The extended mind. Analysis 58 (1): 10-23.

30. Wegner, D.M. (1986). Transactive memory: A contemporary analysis of the group mind. In Theories of group behaviour, eds. B. Mullen and G.R. Goethals, 185-208. New York: Springer-Verlag.

31. Wegner, D.M. (1995). A computer network model of human transactive memory. Social Cognition 13 (3): 319-339.

32. Menary, R. 2007. Cognitive integration: Mind and cognition unbounded. London: Palgrave McMillan.

33. Heersmink, R. 2015. Dimensions of integration in embedded and extended cognitive systems. Phenomenology and the Cognitive Sciences 14 (3): 577-598.

34. Heersmink, R. 2020b. Narrative niche construction: Memory ecologies and distributed narrative identities. Biology and Philosophy 35 (5): 1-23.

35. Bell, G.M., and J. Gemmell. 2009. Total recall: How the e-memory revolution will change everything. New York: Dutton.

36. Hodges, S., L. Williams, E. Berry, S. Izadi, J. Srinivasan, A. Butler, G. Smyth, N. Kapur, and K. Wood. 2006. SenseCam: A retrospective memory aid. In Ubicomp 2006: Ubiquitous Computing, ed. P. Dourish and A. Friday, 177-193. Berlin: Springer.
37. Buckner, C., and J. Garson. 2019. Connectionism. In E. Zalta (ed.), Stanford Encyclopedia of Philosophy. URL: https://plato.stanford.edu/entries/connectionism/\# PC.

38. Hutto, D., and A. Peeters. 2018. The roots of remembering: Radically enactive recollecting. In New directions in the philosophy of memory, ed. K. Michaelian, D. Debus, and D. Perrin, 97-118. London: Routledge.

39. Werning, M. 2020. Predicting the past from minimal traces: Episodic memory and its distinction from imagination and preservation. Review of Philosophy \& Psychology 11 (2): 301-333.

40. Fawns, T. 2019. Blended memory: A framework for understanding distributed autobiographical remembering with photography. Memory Studies. https://doi.org/10. 1177/1750698019829891.

41. Postan, E. 2021. Narrative devices: Neurotechnologies, information, and self-constitution. Neuroethics 14: 231-251.

42. Cerejeira, J., L. Lagarto, and E. Mukaetova-Ladinska. 2012. Behavioral and psychological symptoms of dementia. Frontiers in Neurology. https://doi.org/10.3389/fneur. 2012.00073.

43. Caddell, L., and L. Clare. 2011. I'm still the same person: The impact of early-stage dementia on identity. Dementia 10 (3): 379-398.

44. Addis, D.R., and L.J. Tippett. 2004. Memory of myself: Autobiographical memory and identity in Alzheimer's disease. Memory 12 (1): 56-74.

45. Mills, M. 1998. Narrative identity and dementia: A study of autobiographical memories and emotions. Aldershot: Ashgate Publishing.

46. Piolino, P., B. Desgranges, S. Belliard, V. Matuszewski, C. Lalevée, V. De La Sayette, and F. Eustache. 2003. Autobiographical memory and autonoetic consciousness: triple dissociation in neurodegenerative diseases. Brain 126 (10): 2203-2219.

47. El Haj, M., P. Antoine, J. Nandrino, and D. Kapogiannis. 2015. Autobiographical memory decline in Alzheimer's disease, a theoretical and clinical overview. Ageing Research Reviews, 23, Part B,183-192.

48. Strikwerda-Brown, C., M. Grilli, J. Andrews-Hanna, and M. Irish. 2019. All is the not lost: Rethinking the nature of memory and the self in dementia. Aging Research Reviews, 54, 100932.

49. Surr, C. 2006. Preservation of self in people with dementia living in residential care: A socio-biographical approach. Social Science \& Medicine 62 (7): 1720-1730.

50. Mills, M. 1997. Narrative identity and dementia: A study of emotion and narrative in older people with dementia. Aging and Society 17: 673-698.

51. Schechtman, M. 2012. The story of my (second) life: Virtual worlds and narrative identity. Philosophy and Technology 25 (3): 329-343.

52. Gallagher, S. 2000. Philosophical conceptions of the self: Implications for cognitive science. Trends in Cognitive Science 4 (1): 14-21.

53. Zahavi, D. 2010. Minimal self and narrative self: A distinction in need of refinement. In The embodied self: Dimensions, 
coherence, and disorders, ed. T. Fuchs, H.C. Sattel, and P. Henningsen, 3-20. Stuttgart: Schattauer.

54. Baird, A. 2019. A reflection on the complexity of the self in severe dementia. Cogent Psychology 6 (1). https://doi. org/10.1080/23311908.2019.1574055.

55. Fuchs, T. 2020. Embodiment and personal identity in dementia. Medicine, Health Care \& Philosophy 23: 665-676.

56. Tewes, C. 2021. Embodied selfhood and personal identity in dementia. In Time and body: Phenomenological and psychopathological approaches, ed. C. Tewes and G. Stanghellini, 367-389. Cambridge, UK: Cambridge University Press.

57. Bomilcar, I., E. Bertrand, R. Morris, and D. Mograbi. 2021. The seven selves of dementia. Frontiers in Psychiatry 12: 646050. https://doi.org/10.3389/fpsyt.2021. 646050.

58. Kitwood, T. 1997. The experience of dementia. Aging \& Mental Health 1 (1): 13-22.

59. Newen, A. 2018. The embodied self, the pattern theory of self, and the predictive mind. Frontiers in Psychology 9: 2270. https://doi.org/10.3389/fpsyg.2018.02270.

60. Kontos, P. 2005. Embodied selfhood in Alzheimer's disease: Rethinking person-centred care. Dementia 4 (4): 553-570.

61. Mackenzie, C. 2009. Personal identity, narrative integration, and embodiment. In Embodiment and agency, ed. S. Campbell, L. Maynell, and S. Sherwin, 100-125. Pennsylvania: The Pennsylvania State University Press.

62. Køster, A. 2017. Narrative and embodiment: A scalar approach. Phenomenology and the Cognitive Sciences 16 (5): 893-908.

63. Dings, R. 2019. The dynamic and recursive interplay of embodiment and narrative identity. Philosophical Psychology 32 (2): 186-210.

64. Menary, R. 2008. Embodied narratives. Journal of Consciousness Studies 15 (6): 63-84.

65. Hughes, J. 2001. Views of the person with dementia. Journal of Medical Ethics 27 (2): 86-91.

66. Hughes, J., and A. Beatty. 2013. Understanding the person with dementia: A clinicophilosophical case discussion. Advances in Psychiatric Treatment 19 (5): 337-343.

67. Dennett, D. 1996. Kinds of minds: Towards an understanding of consciousness. New York: Basic Books.

68. Levy, N. 2007. Rethinking neuroethics in the light of the extended mind thesis. American Journal of Bioethics 7 (9): 3-11.

69. Søraker, J. 2007. The moral status of information and information technology: A relational theory of moral status. In Information technology ethics: Cultural perspectives, ed. S. Hongladarom and C. Ess, 1-19. Hershey: Idea Group Publishing.

70. Carter, J.A., and S.O. Palermos. 2016. Is having your computer compromised a personal assault? The ethics of extended cognition. Journal of the American Philosophical Association 2 (4): 542-560.

71. Heersmink, R. 2017b. Extended mind and cognitive enhancement: Moral aspects of cognitive artifacts. Phenomenology and the Cognitive Sciences 16 (1): 17-32.
72. Malafouris, L. 2019. Understanding the effects of materiality on mental health. BJPsych Bulletin 1-6. https://doi. org/10.1192/bjb.2019.7.

73. Piasek, P., K. Irving, and A. Smeaton. 2012. Case study in SenseCam use as an intervention technology for earlystage dementia. International Journal of Computers in Healthcare 1 (4): 304-319.

74. Woodberry, E., G. Browne, S. Hodges, P. Watson, N. Kapur, and K. Woodberry. 2015. The use of a wearable camera improves autobiographical memory in patients with Alzheimer's disease. Memory 23 (3): 340-349.

75. Browne, G., E. Berry, N. Kapur, S. Hodges, G. Smyth, P. Watson, and K. Wood. 2011. SenseCam improves memory for recent events and quality of life in a patient with memory retrieval difficulties. Memory 19 (7): 713-722.

76. Melton, W. 1963. Implications of short-term memory for a general theory of memory. Journal of Verbal Learning and Verbal Behavior 2 (1): 1-21.

77. Loveday, C., and M. Conway. 2011. Using SenseCam with an amnesic patient: Accessing inaccessible everyday memories. Memory 19 (7): 697-704.

78. Bourgeois, M.S. 2007. Memory books and other graphic cuing systems: Practical communication and memory aids for adults with dementia. London: Health Professions Press.

79. Subramaniam, P., B. Woods, and C. Whitaker. 2014. Life review and life story books for people with mild to moderate dementia: A randomised controlled trial. Aging \& Mental Health 18 (3): 363-375.

80. Elfrink, T., S. Zuidema, M. Kunz, and G. Westerhof. 2018. Life story books for people with dementia: A systematic review. International Psychogeriatrics 30 (12): 1797-1811.

81. Damianakis, T., M. Crete-Nishihata, K.L. Smith, R.M. Baecker, and E. Marziali. 2009. The psychosocial impacts of multimedia biographies on persons with cognitive impairments. The Gerontologist 50 (1): 23-35.

82. Smith, K., M. Crete-Nishihata, T. Damianakis, R. Baecker, and E. Marziali. 2009. Multimedia biographies: A reminiscence and social stimulus tool for persons with cognitive impairment. Journal of Technology in Human Services 27 (4): 287-306.

83. Crete-Nishihata, M., R. Baecker, M. Massimi, D. Ptak, R. Campigotto, L. Kaufman, A. Brickman, G. Turner, J. Steinerman, and S. Black. 2012. Reconstructing the past: Personal memory technologies are not just personal and not just for memory. Human-Computer Interaction 27 (1-2): 92-123.

84. Thomson, D.K., and D. Berntsen. 2008. The cultural life script and life story chapters contribute to the reminiscence bump. Memory 16 (4): 420-435.

85. Matthews, S. 2015. Dementia and the power of music therapy. Bioethics 29 (8): 573-579.

86. Gulwadi, G.B. 2013. Establishing continuity of self-memory boxes in dementia facilities for older adults: Their use and usefulness. Journal of Housing for the Elderly 27 (1-2): 105-119.

87. Miles, A.N., L. Fischer-Mogensen, N.H. Nielsen, S. Hermansen, and D. Berntsen. 2013. Turning back the 
hands of time: Autobiographical memories in dementia cued by a museum setting. Consciousness and Cognition 22: 1074-1081.

88. Kirk, M., and D. Berntsen. 2018. A short cut to the past: Cueing via concrete objects improves autobiographical memory retrieval in Alzheimer's disease patients. Neuropsychologia 110: 113-122.

89. Chaudhury, H. 2008. Remembering home: Rediscovering the self in dementia. Baltimore: The Johns Hopkins University Press.

90. Heersmink, R. 2017a. Distributed selves: Personal identity and extended memory systems. Synthese 194 (8): 3135-3151.

91. Heersmink, R. 2018. The narrative self, distributed memory, and evocative objects. Philosophical Studies 175 (8): 1829-1849.

92. Kalnikaite, V., A. Sellen, S. Whittaker, and D. Kirk. 2010. Now let me see where I was: Understanding how lifelogs mediate memory. In CHI: 2010: Proceedings of the ACM SIGCHI conference on human factors in computing systems (pp 2045-2054).

93. Aarts, E. 2004. Ambient intelligence: A multimedia perspective. IEEE MultiMedia 11 (1): 12-19.

94. Lotfi, A., C. Langensiepen, S. Mahmoud, and M. Akhlaghinia. 2012. Smart homes for the elderly dementia sufferers: identification and prediction of abnormal behaviour. Journal of Ambient Intelligence and Humanized Computing 3: 205-218.

95. Novitzky, P., A.F. Smeaton, C. Chen, K. Irving, T. Jacquemard, F. O'Brolcháin, D. O'Mathúna, and B. Gordijn. 2015. A review of contemporary work on the ethics of ambient assisted living technologies for people with dementia. Science and Engineering Ethics 21: 707-765.

96. Mulvenna, M., A. Hutton, V. Coates, S. Martin, S. Todd, R. Bond, and A. Moorhead. 2017. Views of caregivers on the ethics of assistive technology used for home surveillance of people living with dementia. Neuroethics 10 : 255-266.

97. Ienca, M., T. Wangmo, F. Jotterand, R. Kressig, and B. Elger. 2018. Ethical design of intelligent assistive technologies for dementia: A descriptive review. Science and Engineering Ethics 24: 1035-1055.
98. Van den Hoven, J., M. Blauw, W. Pieters, and M. Warnier. 2014. Privacy and information technology. In N. Zalta (Ed.) Stanford encyclopedia of philosophy. URL: http://plato.stanford.edu/entries/it-privacy/.

99. Moyle, W., M. Cooke, E. Beattie, C. Jones, B. Klein, G. Cook, and C. Gray. 2013. Exploring the effect of companion robots on emotional expression in older adults with dementia: A pilot randomized controlled trial. Journal of Gerontological Nursing 39 (5): 46-53.

100. Sharkey, A. and N. Wood. 2014. The Paro seal robot: demeaning or enabling? In Proceedings of the AISB, London, UK (pp 1-4).

101. Pou-Prom, C., S. Raimondo, F. Rudzicz. 2020. A conversational robot for older adults with Alzheimer's disease. ACM Transactions on Human-Robot Interaction 21. https://doi.org/10.1145/3380785.

102. Smart, P. 2020. The Joi of holograms. In Blade Runner 2049: A philosophical exploration, ed. T. Shanahan and P. Smart, 127-148. London: Routledge.

103. McCarroll, C. 2018. Remembering from the outside: Personal memory and the perspectival mind. Oxford: Oxford University Press.

104. Strawson, G. 2004. Against narrativity. Ratio 17 (4): 428-452.

105. Strawson, G. 2011. The minimal subject. In The Oxford handbook of the self, ed. S. Gallagher, 253-278. Oxford: Oxford University Press.

106. Tajfel, H. (1972). Social categorization. English manuscript of 'La catégorisation sociale'. In S. Moscovici (Ed.), Introduction à la psychologie sociale (pp. 272302). Paris: Larousse.

107. Heersmink, R. 2021. Materialised identities: Cultural identity, collective memory, and artifacts. Review of Philosophy and Psychology. https://doi.org/10.1007/ s13164-021-00570-5.

Publisher's Note Springer Nature remains neutral with regard to jurisdictional claims in published maps and institutional affiliations. 